\title{
Risk assessment of heavy metals in soil based on the geographic information system-Kriging technique in Anka, Nigeria
}

\author{
Onisoya Johnbull, Bassim Abbassi ${ }^{\dagger}$, Richard G. Zytner \\ School of Engineering, University of Guelph, 50 Stone Rd E, Guelph, ON, N1G 2W1, Canada
}

\section{ABSTRACT}

Soil contaminated with heavy metals from artisanal gold mining in Anka Local Government Area in Northwestern Nigeria was investigated to evaluate the human health risk as a result of heavy metals. Measured concentration of heavy metals and exposure parameters were used to estimate human carcinogenic and non-carcinogenic risk. GIS-based Kriging method was utilized to create a prediction maps of human health risks and probability maps of heavy metals concentrations exceeding their threshold limits. Hazard index calculation showed that 21 out of 23 locations are posing non-cancer risk for children. Adults and children are at high cancer risk in all locations as the total cancer risk exceeded $1 \times 10^{-6}$ (the lower limit CTR value). Kriging model showed that only a very small area in Anka has a hazard index of less than unity and cumulative target risk of less than $1 \times 10^{-4}$, indicating a significant carcinogenic and non-carcinogenic risks for children. The probability of heavy metals to exceed their threshold concentrations around the study area was also found to be high.

Keywords: Carcinogenic, Heavy metals, Human risk assessment, Kriging, Non-carcinogenic

\section{Introduction}

Heavy metals (HMs) occur naturally in the environment, however, the concentration of some HMs has increased tremendously since the beginning of the industrial revolution due to many industrial activities. One of these activities is artisanal gold mining. Artisanal gold mining provides an important source of livelihood, especially for developing countries and regions where other sources of revenue are limited. This is true for the inhabitants in Anka in northwestern Nigeria, where gold mining and farming is the only major source of livelihood. Miners recruit men, women and children as part of the labor workforce for mining and processing mineral ore.

The mining practice involves mining the ore, transportation of the ore to a processing site (sometimes in their backyard), crushing and pulverizing with locally fabricated tools and machine, and amalgamation of the mineral ore with mercury. Subsequently, the mine tailings are indiscriminately dumped in residential areas and constitute a major source of lead, mercury and others HMs [1]. Indiscriminate dumping of HMs around residential soils results in easy transfer to humans by ingestion, inhalation, or dermal absorption, and further accumulates in fatty tissues [2]. Regrettably, mining activities have negative impacts on the environment and human health because HMs released during mining are extremely toxic, bio-accumulative, and resistant to bio-chemical degradation and can interface with the normal functioning of the nervous system, endocrine system, immune system, hematopoietic function, normal cellular metabolism [2, 3].

In March 2010 elevated blood lead level (BLL) was discovered in children due to artisanal gold mining in the Anka Local Government Area (LGA) in Zamfara State, in northwestern Nigeria, which led to mass lead poisoning. This resulted in an unprecedented outbreak with over 400 deaths and thousands affected, especially children under the age of 5 years [4, 5]. Furthermore, due to the undulating topography in Anka, mine tailings can be easily washed to farther location such as farmlands, rivers and other water bodies during the rainy season. Additionally, irrigation and wind can also aid the distribution and accumulation of HMs to other locations. A previous study of HMs in Anka indicated that hazard risk ranking of $\mathrm{HMs}$ followed the order: $\mathrm{Pb}>\mathrm{As}$ $>\mathrm{Hg}>\mathrm{Cd}>\mathrm{Mn}$ [6]. Additional, research determined that the concentration of HMs in Zamfara state were also far beyond the recommended guideline threshold [7-9]. For example, the total concentrations of $\mathrm{Pb}$ and $\mathrm{Cd}$ recorded were reported to be 2,246.6
This is an Open Access article distributed under the terms of the Creative Commons Attribution Non-Commercial License (http://creativecommons.org/licenses/by-nc/3.0/) which permits unrestricted non-commercial use, distribution, and reproduction in any medium, provided the original work is properly cited.

Copyright (C) 2019 Korean Society of Environmental Engineers
Received March 31, 2018 Accepted July 12, 2018

${ }^{\dagger}$ Corresponding author

Email: babbassi@uoguelph.ca

Tel: +1-519-824-4120 Fax: +1-519-836-0227

ORCID: 0000-0002-0770-9800 
and $68.7 \mathrm{mg} / \mathrm{kg}$, respectively. These are greater than the threshold values for $\mathrm{Pb}(300 \mathrm{mg} / \mathrm{kg}$ ) and $\mathrm{Cd}(3 \mathrm{mg} / \mathrm{kg})$ [9].

All of these studies based their findings on the concentration of HMs at the sites of contamination. None of these studies attempted to interpolate or extrapolate HMs concentrations to cover a large study area. The application of geographic information system (GIS) has been introduced in the field of environmental risk assessment as an important tool and analysis method [10-13]. These studies indicated that GIS tool using Kriging method can adequately account for spatial heterogeneity of contaminants.

Kriging was originally used by miners and geologists, however, recent applications of Kriging has been used to approximate hurricane wave, soil risk assessment, rainfall and many other fields $[14,15]$. Kriging is often more preferred to deterministic methods because it does not only depend on the distance between the measured locations, but also on the spatial autocorrelation among the measured values around the prediction location [16]. Kriging has been successfully applied in mapping soil pollution caused by HMs [17, 18]. The basic principle behind Kriging is closely related to Tobler first law of geography, which states that "everything is related to everything else, but near things are more related than distant things" [19]. Therefore measured samples that are distributed closely in space are more similar to measured samples that are further apart [18-20]. Kriging uses semi-variogram or covariance function to describe the spatial autocorrelation among the data around the prediction location [18]. The semi-variogram or covariance function can be fitted with circular, spherical, ex- ponential, Gaussian, stable, J-Bessel or K-Bessel functions to improve the prediction.

In this work, the main goal was to apply a GIS-based Kriging technique to quantify human environmental risk of HMs pollution in Anka in Nigeria. This will enable a quantification of risk in a large spatial boundary considering the heterogeneity of contaminants' sources and concentrations.

\section{Study Area}

Anka is one of the 14 Local Governments of Zamfara State in Nigeria. It is situated in the northwestern part of Nigeria with a location coordinate of latitudes $11^{\circ} 40^{\prime} 0^{\prime \prime}$ and $12^{\circ} 20^{\prime} 0^{\prime \prime}$ North and longitudes $5^{\circ} 50^{\prime} 0^{\prime \prime}$ and $6^{\circ} 20^{\prime} 0^{\prime \prime}$ East [20]. Anka occupies an area of 2,746 $\mathrm{km}^{2}$ and has a population of 142,280 [21]. Anka has many areas with significant concentrations of HMs in the soil and rocks. Gold mining in Zamfara state has been ongoing for decades, but was not extensive or lucrative, however, a surge in the price of Gold from 2009 to May 2012 led to a revived interest consequently leading to a substantial increase in mining activities [5]. This resulted in a renewed interest in mining in Zamfara state. Anka has two major seasons; rainy season and dry season, food crops produced during these seasons include cowpea, sorghum peanut, millet, lettuce, and cabbage [4]. These food crops may phytoaccumulate HMs in the roots, shoots, leaves, and fruits that could consequently pose a threat to humans.

Table 1. Concentration of Heavy Metals at Different Sample Site [1]

\begin{tabular}{|c|c|c|c|c|c|c|}
\hline \multirow{2}{*}{ Sample Area } & \multicolumn{2}{|c|}{ Location } & \multicolumn{4}{|c|}{ Concentration in ppm } \\
\hline & Latitude & Longitude & $\mathbf{P b}$ & $\mathrm{Hg}$ & As & Cd \\
\hline Mining site 1 & 12.01939 & 5.926728 & 1,946 & 2.840 & 98.03 & BDL \\
\hline Mining site 2 & 12.07627 & 5.911378 & 1,218 & 4.448 & 99.17 & 4.383 \\
\hline Mining site 3 & 12.03464 & 5.815947 & 2,637 & 7.931 & 97.90 & 4.522 \\
\hline Mineral ore processing site 1 & 12.01534 & 5.951822 & 1,740 & 7.380 & 82.41 & 1.779 \\
\hline Mineral ore processing site 2 & 12.06043 & 5.942489 & 3,193 & 9.011 & 127.2 & 6.874 \\
\hline Mineral ore processing site 3 & 12.0528 & 5.901403 & 3,920 & 10.277 & 100.6 & 8.655 \\
\hline Mineral ore processing site 4 & 12.01876 & 5.824411 & 1,694 & 7.399 & 85.37 & 2.786 \\
\hline Mineral ore processing site 5 & 12.02719 & 5.805308 & 1,960 & 8.388 & 84.31 & 3.551 \\
\hline Mineral ore processing site 6 & 12.15282 & 5.905183 & 4,152 & 12.924 & 173.2 & 10.01 \\
\hline Village square 1 & 11.98747 & 5.968578 & 1,432 & 5.481 & 124.2 & BDL \\
\hline Village square 2 & 12.00891 & 5.965644 & 17.36 & 4.577 & 12.49 & 5.740 \\
\hline Village square 3 & 12.04889 & 5.872586 & 289.7 & 2.985 & 27.14 & $\mathrm{BDL}$ \\
\hline Village square 4 & 11.98649 & 5.834178 & 3,326 & 12.325 & 110.4 & 6.870 \\
\hline Village square 5 & 12.13148 & 5.98165 & 19.57 & 4.149 & 16.5 & 0.0097 \\
\hline Farmland 1 & 12.01217 & 5.988011 & 30.26 & 3.892 & 38.2 & 5.447 \\
\hline Farmland 2 & 12.03851 & 5.985614 & 463.2 & 5.887 & 59.56 & BDL \\
\hline Farmland 3 & 11.99038 & 5.942492 & 25.73 & - & 24.05 & 2.410 \\
\hline Farmland 4 & 12.07082 & 5.847828 & 19.80 & - & 24.7 & BDL \\
\hline Farmland 5 & 12.10008 & 5.859142 & 2,892 & - & 96.91 & 7.843 \\
\hline Uncultivated land 1 & 11.98301 & 5.989842 & 6,909 & - & 7.434 & 4.658 \\
\hline Uncultivated land 2 & 11.97589 & 5.927358 & 20.60 & - & 23.44 & 0.0466 \\
\hline Uncultivated land 3 & 11.99427 & 5.871408 & 770.3 & - & 98.57 & 1.133 \\
\hline Uncultivated land 4 & 12.10012 & 5.972408 & 447.4 & - & 55.97 & 0.0656 \\
\hline
\end{tabular}

$\mathrm{BDL}=$ below detection limit 


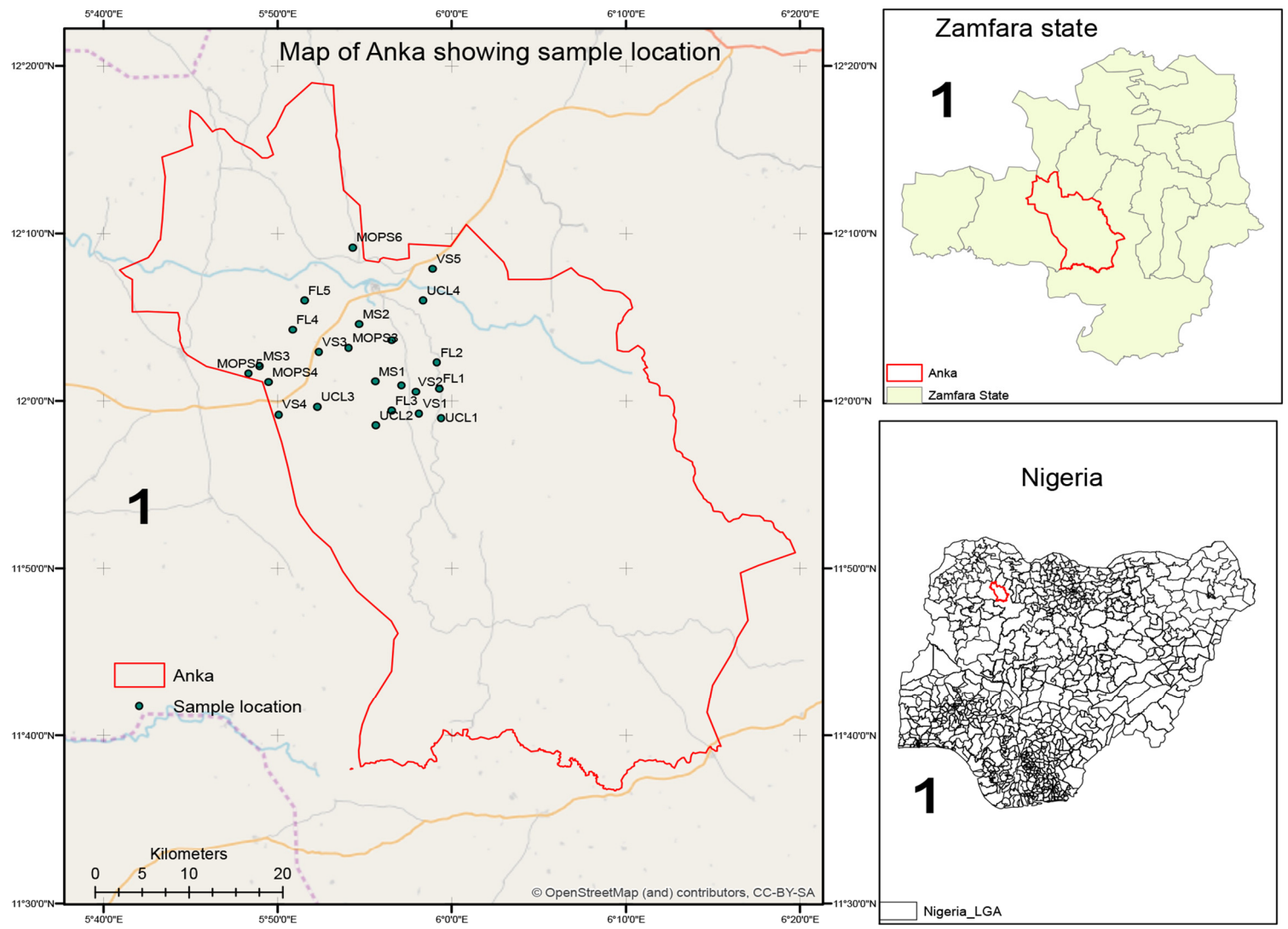

Fig. 1. Map of Nigeria showing Zamfara state and the study area.

The concentration of HMs in different locations in Anka has been reported by Uriah et al. [1]. The location of Anka and where the samples were taken for analysis are shown in Fig. 1. For the purpose of clearly displaying the measured location on the maps, the following abbreviations MS, MOPS, VS, FL and UCL will be used to represent mining site, mineral ore processing site, village square, and farmland and uncultivated land, respectively. Table 1 shows a summary of the concentration of HMs in the different locations in the study area. These values were used in this investigation to run the Kriging model and quantify the human health risks.

\section{Methodology}

\subsection{Human Health Risk Assessment Method}

To estimate the carcinogenic risk and the non-carcinogenic risk, the method developed by the USEPA for calculation of human health risk assessment was used [22]. Having identified the chemical of potential concern as $\mathrm{Pb}, \mathrm{Hg}$, As and $\mathrm{Cd}$, the next step is to determine the pathway of exposure and the level of exposure. The intake is called chronic daily intake (CDI) for non-carcinogenic chemicals, whereas for carcinogenic chemicals, the intake is called lifetime average daily dose (LADD). The three exposure routes, which include soil ingestion, inhalation, and dermal absorption, can be estimated using the Eq. (1) to (3).

$$
\begin{gathered}
\text { Soil ingestion rate }\left(\frac{\mathrm{mg}}{\mathrm{kg} \text {.day }}\right)=\frac{\mathrm{C}_{\text {soil }} \times \mathrm{IngR} \times \mathrm{EF} \times \mathrm{ED}}{\mathrm{BW} \times \mathrm{AT}} \times \mathrm{CF} \\
\text { Inhalation rate }\left(\frac{\mathrm{mg}}{\mathrm{kg} \text {.day }}\right)=\frac{\mathrm{C}_{\text {soil }} \times \mathrm{InhR} \times \mathrm{EF} \times \mathrm{ED}}{\mathrm{PEF} \times \mathrm{BW} \times \mathrm{AT}}
\end{gathered}
$$

$$
\begin{aligned}
& \text { Dermal absorption rate }\left(\frac{\mathrm{mg}}{\mathrm{kg} \cdot \mathrm{day}}\right)= \\
& \qquad \frac{\mathrm{C}_{\text {soil }} \times \mathrm{SA} \times \mathrm{FE} \times \mathrm{AF}_{\text {soil }} \times \mathrm{ABS} \times \mathrm{EF} \times \mathrm{ED}}{\mathrm{BW} \times \mathrm{AT}} \times \mathrm{CF}
\end{aligned}
$$

where, $C_{\text {soil }}$ is the concentration of the contaminant in the soil (mg/kg.d), $I n g R$ is the ingestion rate (mg/day), $I n h R$ is the inhalation rate $\left(\mathrm{m}^{3} /\right.$ day), $E F$ is the exposure frequency (day/year), $E D$ is the exposure duration (year), $B W$ is the average body weight $(\mathrm{kg})$, $A T$ is the average time (day), $S A$ is the skin surface area $\left(\mathrm{cm}^{2}\right)$, $A F_{\text {soil }}$ is the soil adherence factor $\left(\mathrm{mg} / \mathrm{cm}^{2}\right), A B S$ is the dermal absorption factor (unitless), $F E$ is the dermal exposure ratio (unitless), $P E F$ is the particulate emission factor $\left(\mathrm{m}^{3} / \mathrm{kg}\right)$ and $C F$ is the conversion factor [22]. The value for the exposure parameters are given in Table 2 . 
Table 2. Parameters Used in the Exposure Rate Model

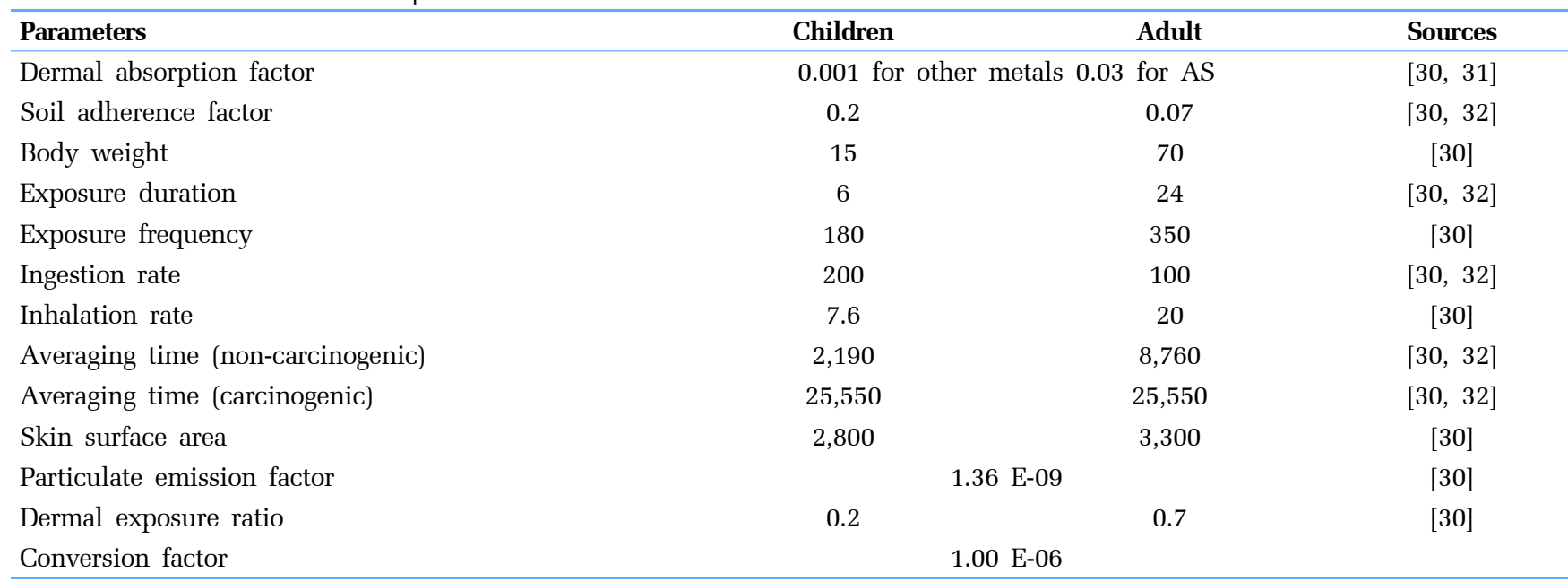

Table 3. Reference Dose and Cancer Slope Factor of Some Heavy Metals

\begin{tabular}{cccccccc}
\hline Metals & $\begin{array}{c}\text { Oral Reference } \\
\text { dose }\end{array}$ & $\begin{array}{c}\text { Inhalation Reference } \\
\text { dose }\end{array}$ & $\begin{array}{c}\text { Dermal Reference } \\
\text { dose }\end{array}$ & $\begin{array}{c}\text { CSF } \\
\text { Oral }\end{array}$ & $\begin{array}{c}\text { CSF } \\
\text { Inhalation }\end{array}$ & $\begin{array}{c}\text { CSF } \\
\text { Dermal absorption }\end{array}$ & $\begin{array}{c}\text { Sources } \\
\text { Doser }\end{array}$ \\
\hline $\mathrm{Pb}$ & $4.00 \mathrm{E}-03$ & $3.50 \mathrm{E}-03$ & $5.25 \mathrm{E}-04$ & $8.50 \mathrm{E}-03$ & $4.20 \mathrm{E}-02$ & $8.50 \mathrm{E}-06^{*}$ & {$[33,34]$} \\
$\mathrm{Hg}$ & $3.00 \mathrm{E}-04$ & $8.60 \mathrm{E}-05$ & $2.10 \mathrm{E}-05$ & & & & {$[33,34]$} \\
$\mathrm{As}$ & $3.00 \mathrm{E}-04$ & $4.29 \mathrm{E}-06$ & $3.00 \mathrm{E}-04$ & 1.5 & $1.50 \mathrm{E}+01$ & $3.66 \mathrm{E}+00$ & {$[33,34]$} \\
$\mathrm{Cd}$ & $1.00 \mathrm{E}-03$ & $2.86 \mathrm{E}-06$ & $2.50 \mathrm{E}-05$ & - & $6.30 \mathrm{E}+00$ & - & {$[33,34]$} \\
\hline
\end{tabular}

* Calculated using Eq. (6), no data available [34]

\subsubsection{Non-carcinogenic risk characterization}

The linear numerical models used to compute the non-cancer risk assessment was adapted from the USEPA Exposure factors handbooks [22]. The non-carcinogenic risk is typically expressed in terms of hazard quotient (HQ) and hazard index (H). The HQ for a single contaminant is determined by dividing the estimated daily intake by the reference dose (Rfd) of the contaminant. Several simultaneous exposures to sub-threshold levels could add up to cause adverse effects. Therefore summing the HQ of each HM having adverse effects on the same organ or similar toxic effect can indicate whether the risk is acceptable or not. HI is the integration of HQ's from all exposure pathways having similar toxic effects. Generally, an HQ of less than 0.2 is considered acceptable while a value of more than 0.2 is considered unacceptable. Similarly, an HI of greater than unity from various pathways is considered unacceptable which means that the exposed population may experience adverse health effect and risk management measures should be implemented while $\mathrm{HI}$ of less than unity is considered negligible [23-25]. Mathematically, the HQ and HI can be determined using Eq. (4) and (5) [25].

$$
\text { Hazard Quotient }=\frac{\text { Chronic daily intake rate }}{\text { Reference dose }}
$$

Hazard Index(HI) =

HQ pathway $1+$ HQ pathway $2 \ldots . .+$ HQ pathway $n$ where the reference dose and cancer slope factor (CSF) for dermal exposure are not available, extrapolation can be found by multiplying the oral reference dose by the gastro-intestinal absorption factor and by multiplying the oral cancer slope by the gastro-intestinal absorption factor according to Eq. (6) [26].

$$
\begin{aligned}
& \text { Dermally adjusted CSF }= \\
& \text { gastro }- \text { intestinal absorption } \times \text { Oral CSF }
\end{aligned}
$$

Yuswir et al. [27] cited the gastro-intestinal absorption factor of several HMs. The reference doses as well as the cancer slope factors are given in Table 3.

\subsubsection{Carcinogenic risk characterization}

The carcinogenic risk is estimated as the incremental probability of the occurrence of cancer over a lifetime as a result of exposure to a potential carcinogenic contaminant. Incremental excess lifetime cancer risk (IELCR) is the terminology for characterizing carcinogenic risk and it can be calculated using Eq. (7).

$$
\mathrm{IELCR}=\mathrm{LADD} \times \mathrm{CSF}
$$

To sum the carcinogenic effect resulting from exposure to two or more carcinogens, the cumulative target risk (CTR) can be calculated from the Eq. (8).

$$
\mathrm{CTR}=\sum_{\mathrm{i}} \mathrm{IELCR}_{\mathrm{i}}
$$


When CTR exceeds $1 \times 10^{-4}-1 \times 10^{-6}$ further chemical-specific assessment is required, however, when CTR fall below $1 \times 10^{-4}$ $1 \times 10^{-6}$ no action is required from a human health perspective [25]. These thresholds have been adopted because they represent the risk at the exposed population that is likely going to have an adverse health effect or not. The values $1 \times 10^{-4}$ and $1 \times 10^{-6}$ represent the upper and lower limits of human health risk, beyond which there is a statistical significant evidence of adverse health effect [25]. The upper limit value $\left(1 \times 10^{-4}\right)$ has been used in this investigation as a reference CTR.

\subsection{Kriging for Geostatistical Analysis}

In addition to risk assessment, ArcGIS 10.5.2 was used to show the spatial distribution and variability of the HMs contamination in the soil. This has been done by importing an excel file containing the location and concentration of each HMs from the measured locations in ArcMap and creating a points event layer based on $\mathrm{x}$ - and $\mathrm{y}$-coordinates (longitude and latitude in decimal degrees) of the sample location and by setting the Coordinate system to World Geodesic System (WGS1984). Subsequently, the event layer was exported to create a permanent layer containing an attribute table of HM concentrations for each of the measured locations. The created layer containing the attribute table of the HMs enables different analysis to be performed on the dataset on ArcGIS. The use of ArcGIS is important to display an aerial view of the spatial distribution of the contamination of HMs as well as HI and HQ across the study location.

Geostatistical extension in ArcGIS 10.5.2 was used in the implementation of ordinary Kriging for the human health risk assessment prediction map and probability Kriging for the probability map. As well as choosing a different model that best described the spatial autocorrelation for both the prediction map and the probability map to fit the semi-variogram, specific parameters of the semi-variogram differ between maps. The choice of model used was based on the model that gave minimal prediction error when compared to other available models (based on root-mean-square, root-mean-square standardize, average standard error and cross validation).

\section{Results}

The concentration of HMs at different locations in Anka is presented in Table 1. The concentration of $\mathrm{Pb}$ varies greatly from $19.8 \mathrm{ppm}$ to $6,909 \mathrm{ppm}$. Also, the mining sites and mineral ore processing sites have very high HMs concentrations across all the measured areas. Hg, As and Cd have a relatively low concentration but still high enough to be toxic to human and biological communities in the ecosystem. The concentrations of the HMs are highest in the mineral ore-processing sites except for the concentration of $\mathrm{Pb}$ in the Uncultivated Land 1 at 6,909 ppm. Moreover, the average

Table 4. Carcinogenic and Non-carcinogenic Risk of HM for Child and Adult

\begin{tabular}{|c|c|c|c|c|c|}
\hline \multirow{2}{*}{ Sample area } & \multirow{2}{*}{ Abbr. } & \multicolumn{2}{|c|}{ Total non-cancer risk } & \multicolumn{2}{|c|}{ Total cancer risk } \\
\hline & & HI Adult & HI Children & CTR Adult & CTR Children \\
\hline Mining site 1 & MS1 & 1.135 & 10.610 & 9.647 E-05 & $1.799 \mathrm{E}-04$ \\
\hline Mining site 2 & MS2 & 0.902 & 8.430 & 9.385 E-05 & $1.750 \mathrm{E}-04$ \\
\hline Mining site 3 & MS3 & 1.404 & 13.130 & 9.981 E-05 & $1.862 \mathrm{E}-04$ \\
\hline Mineral ore processing site 1 & MOPS1 & 1.016 & 9.499 & 8.162 E-05 & $1.522 \mathrm{E}-04$ \\
\hline Mineral ore processing site 2 & MOPS2 & 1.739 & 16.260 & 1.285 E-04 & 2.397 E-04 \\
\hline Mineral ore processing site 3 & MOPS3 & 1.878 & 17.550 & 1.086 E-04 & 2.026 E-04 \\
\hline Mineral ore processing site 4 & MOPS4 & 1.016 & 9.491 & 8.401 E-05 & 1.567 E-04 \\
\hline Mineral ore processing site 5 & MOPS5 & 1.109 & 10.360 & 8.440 E-05 & 1.574 E-04 \\
\hline Mineral ore processing site 6 & MOPS6 & 2.305 & 21.540 & 1.740 E-04 & 3.246 E-04 \\
\hline Village square 1 & VS1 & 1.089 & 10.180 & 1.171 E-04 & $2.184 \mathrm{E}-04$ \\
\hline Village square 2 & VS2 & 0.093 & 0.868 & 1.114 E-05 & 2.078 E-05 \\
\hline Village square 3 & VS3 & 0.238 & 2.227 & 2.546 E-05 & 4.750 E-05 \\
\hline Village square 4 & VS4 & 1.725 & 16.110 & 1.143 E-04 & $2.132 \mathrm{E}-04$ \\
\hline Village square 5 & VS5 & 0.102 & 0.949 & 1.470 E-05 & 2.742 E-05 \\
\hline Farmland 1 & FL1 & 0.212 & 1.973 & 3.396 E-05 & 6.333 E-05 \\
\hline Farmland 2 & FL2 & 0.460 & 4.299 & 5.502 E-05 & $1.026 \mathrm{E}-04$ \\
\hline Farmland 3 & FL3 & 0.122 & 1.143 & 2.141 E-05 & 3.994 E-05 \\
\hline Farmland 4 & FL4 & 0.120 & 1.119 & 2.196 E-05 & $4.096 \mathrm{E}-05$ \\
\hline Farmland 5 & FL5 & 1.456 & 13.610 & 1.002 E-04 & $1.869 \mathrm{E}-04$ \\
\hline Uncultivated land 1 & UCL1 & 2.433 & 22.750 & 4.109 E-05 & $7.663 \mathrm{E}-05$ \\
\hline Uncultivated land 2 & UCL2 & 0.114 & 1.068 & 2.085 E-05 & 3.889 E-05 \\
\hline Uncultivated land 3 & UCL3 & 0.719 & 6.718 & 9.108 E-05 & $1.699 \mathrm{E}-04$ \\
\hline Uncultivated land 4 & UCL4 & 0.411 & 3.839 & 5.176 E-05 & 9.656 E-05 \\
\hline
\end{tabular}




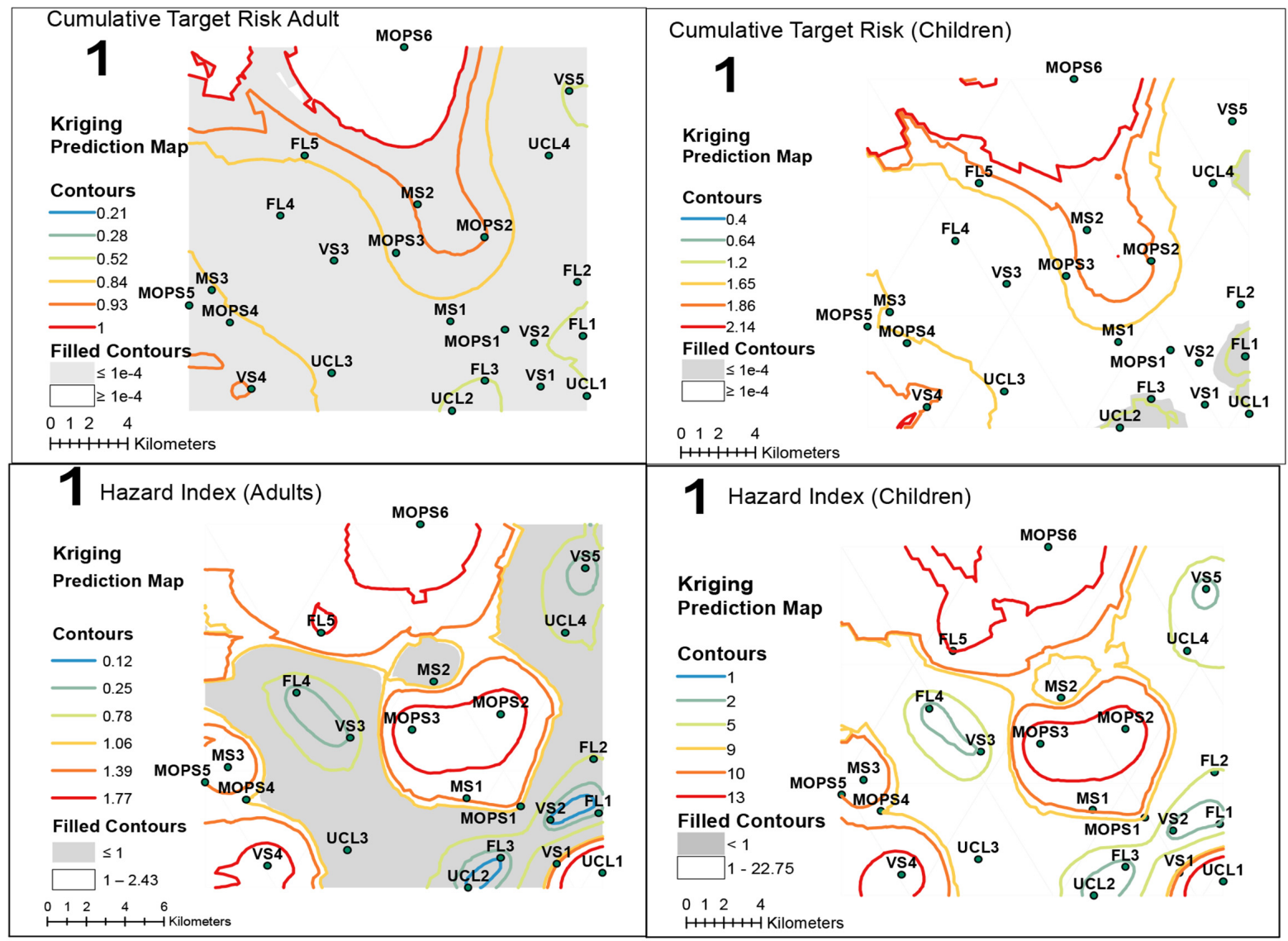

Fig. 2. Hazard index and normalized cumulative target risk for children and adult.

concentration of HMs in the measured locations decrease in the following order: (1) for $\mathrm{Pb}$, Farmlands < Village squares < Uncultivated lands < Mining sites < Mineral ore processing sites; (2) for Hg, Uncultivated lands < Farmlands < Mining sites < Village squares < Mineral ore processing sites; (3) for As, Uncultivated lands < Farmlands < Village squares < Mining sites $<$ Mineral ore processing sites; (4) for Cd, Uncultivated lands $<$ Mining sites < Village squares < Farmlands < Mineral ore processing sites.

\subsection{Human Health Risk Assessment and Kriging Prediction}

The calculated value of HI and CTR using Eq. (1)-(8) are presented in Table 4. The table shows clearly that only two sites (VS2 and VS5) out 23 sites in Anka exhibited a negligible HI for children (HI less than unity), as opposed to 11 sites for adults. This result is explicitly linking environmental harm to high risk to Anka's children. As previously mentioned, the total cancer risk will be deemed to be "essentially negligible" where the estimated total CTR is less than the limits of human health risk. At an upper limit CTR value of $1 \times 10^{-4}$, Table 4 shows that nine sites have negligible cancer risk to children. If lower limit value is selected $\left(1 \times 10^{-6}\right)$, no site in the study area exhibits a negligible cancer risk to both children and adults. The spatial distribution of the HI (non-carcinogenic risk) and the CTR (Carcinogenic risk) of HMs in and around the measured locations are shown in Fig. 2.

\subsection{Kriging Prediction}

The contours for CTR shown in Fig. 2. have been normalized by dividing the total cancer risk for each study group (adult and children) by $1 \times 10^{-4}$ (de Minimis risk) [25]. The value $1 \times 10^{-4}$ represents the upper limit of human health risk, beyond which there is a statistical significant evidence of adverse health effect [25]. Therefore, any area on the map with CTR above unity, represents area with significant evidence of adverse health effect and vice versa. Generally, the risk is higher for children than for an adult. This is because children are more vulnerable to chemical attack due to their physiology and morphology and exposure pathway.

Fig. 2 shows that only very few areas have a CTR $\leq 1$ or $1 \times 10^{-4}$ and $\mathrm{HI}<1$ for children. This indicates that the majority of the study area showed that there is a significant risk for carcinogenic and non-carcinogenic adverse health effect for children. It can also be seen that areas corresponding to high CTR and HI are 
around the mineral ore processing sites or mining sites. Therefore, in order to reduce the risk posed by HMs through artisanal gold mining, children should stay clear of mining areas and mineral ore processing sites. Furthermore, any remediation strategy should prioritize areas such as VS4 and VS1 which have relatively higher risk and sizable number of inhabitants. In contrast, for adults, close to half of the study area indicated no significant non-carcinogenic risk of adverse health effect, and only about a quarter of the study area indicated significant carcinogenic risk of adverse health effects. The average $\mathrm{HI}$ for children and adult are 8.86 and 0.95 , respectively. The average carcinogenic risk for adult and children are $7.27 \times 10^{-5}$ and $1.36 \times 10^{-4}$, respectively. This result validates why Doctors without Borders focused on children aged five years and below during the $\mathrm{Pb}$ poisoning outbreak as children were the most susceptible group [5].

Since some areas classified by the CTR method as having acceptable risk level, are at the same time classified by the $\mathrm{HI}$ methods as have unacceptable risk level, it can be deduced that HI method is the most conservative method of human health risk assessment. Hence, even though children and adults may not be exposed to significant doses to cause cancer, they might still experience adverse non-carcinogenic health effect.

\subsection{Kriging Probability Map}

ArcGIS was used to develop a probability map, which was used to evaluate the probability that the concentration of HMs would exceed certain stated threshold limits (Fig. 3). The threshold values used to calculate the probabilities in the Kriging model for $\mathrm{Pb}$, As, Cd, and $\mathrm{Hg}$ were 100, 20, 3, and 0.8, respectively [28, 29]. Fig. 3 shows that the probability of $\mathrm{Pb}, \mathrm{Hg}$, and As to exceed their respective threshold limit in the mineral ore processing sites and its immediate surrounding is almost $100 \%$. As for $\mathrm{Cd}$, the probability of MOPS1 and MOPS4 to exceed their threshold limit were found to range between 0 and 16\%, while MOPS2, 3 and 5 show a higher probability of about $84-100 \%$. VS4 shows a very high probability of $100 \%$ of $\mathrm{Pb}, \mathrm{Hg}$, As and $\mathrm{Cd}$.

Furthermore, Fig. 3 shows that only three areas (VS5, VS2 and UCL1) within the vicinity of measured locations showed a probability of less than $42 \%$ for As to exceed its threshold value. However, the majority of the study area showed a probability greater than $90 \%$ of As to exceed the threshold value. In the same way for $\mathrm{Cd}$, the majority of measured location within the study areas has a probability of less than $50 \%$ to exceed the threshold value. However, more than half of the study area showed a probability of greater than $50 \%$ of $\mathrm{Cd}$ to exceed its threshold value. Additionally, the majority of areas have $\mathrm{Hg}$ and $\mathrm{Pb}$ probability greater than 93\% to exceed their threshold. However, while Hg has FL3-5,
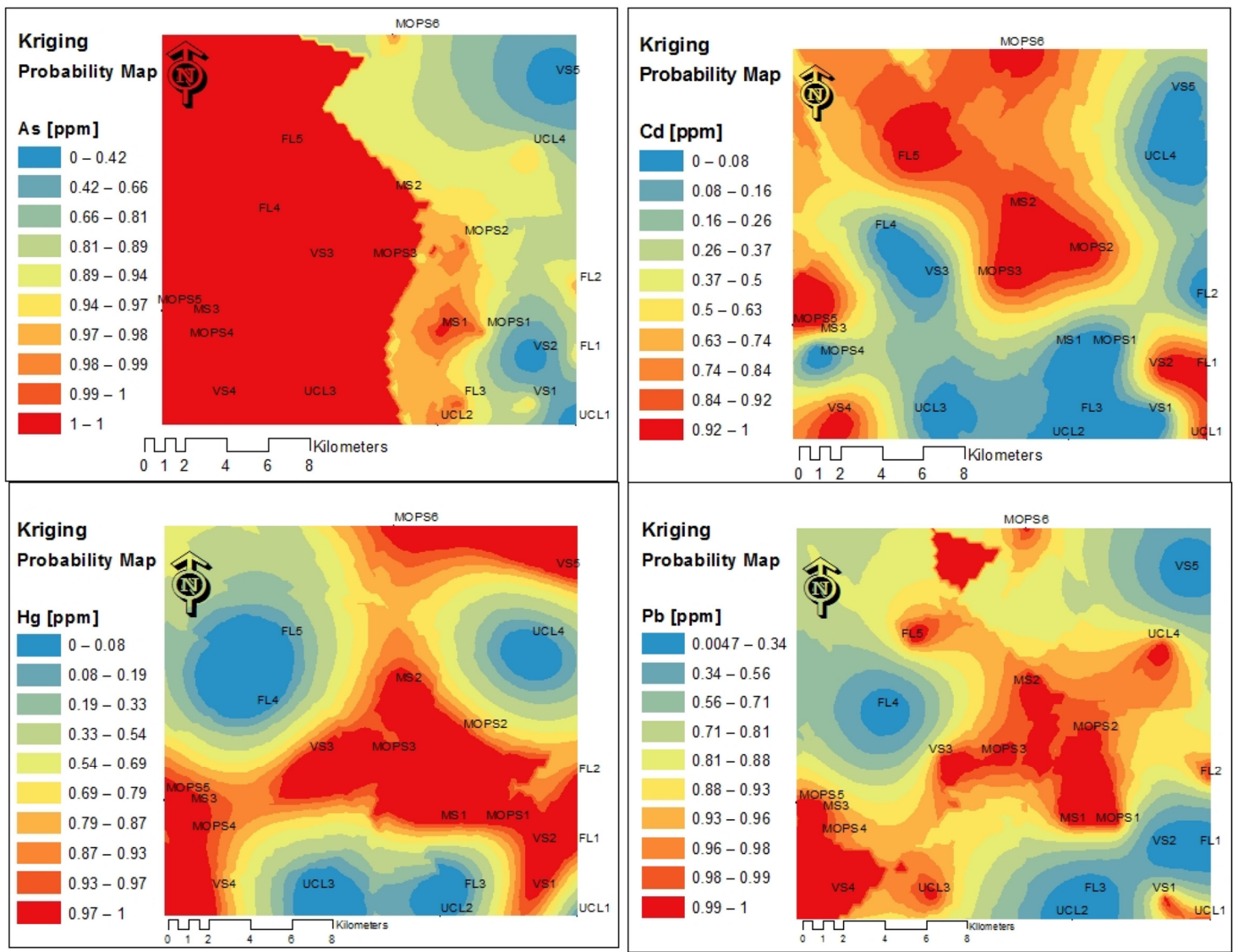

Fig. 3. The probability of HMs concentration to exceed their threshold limits. 
and, UCL1-4 in areas with probability in the range of $0-19 \%$ of $\mathrm{Hg}$ to exceed its threshold value, Pb has VS5, VS2, FL1, FL3, FL4 and UCL2 in areas with probability in the range of $0.47-34 \%$ of $\mathrm{Hg}$ to exceed its threshold value.

\section{Conclusions}

In this work, HMs concentration from uncultivated lands, farmlands, village squares, mining sites and mineral ore processing sites in Anka in Northwestern Nigeria were studied with the purpose of quantifying and evaluating the human health risk heavy metal from artisanal gold mining possess to the inhabitants of Anka. The results showed that arsenic, mercury, and cadmium generally have their highest concentration in the mineral ore processing sites. GIS Kriging was used to show that majority of the study locations have a significant risk for non-carcinogenic and carcinogenic risk adverse health effect for children. In contrast, for adults, close to half of the study area indicated no significant non-carcinogenic risk of adverse health effect, and only about a quarter of the study area indicated significant carcinogenic risk of adverse health effects. Furthermore, probability Kriging indicated high probability of $\mathrm{Hg}$, $\mathrm{Cd}$, As and $\mathrm{Pb}$ to exceed their threshold concentration around the study area, which point out that HMs are likely going to cause serious health issues for the residents of the village especially among sensitive groups. Ultimately, this research will help environmental engineers to delineate vulnerable areas that should be prioritized for remediation.

\section{References}

1. Uriah L, Kenneth T, Rhoda G, Ayuba M. Lead and mercury contamination associated with artisanal gold mining in Anka, Zamfara State, North Western Nigeria: The continued unabated Zamfara lead poisoning. J. Earth Sci. Eng. 2013;3:764-775.

2. Zhao L, Xu Y, Hou H, Shangguan Y, Li F. Source identification and health risk assessment of metals in urban soils around the Tanggu chemical industrial district, Tianjin. China Sci. Total Environ. 2014;468-469:654-662.

3. Wei B, Yang L. A review of heavy metal contaminations in urban soils, urban road dusts and agricultural soils from China Microchem. J. 2010;94:99-107.

4. Olujimi O, Oputu O, Fatoki O, Opatoyinbo E, Aroyewun A, Baruani J. Heavy metals speciation and human health risk assessment at an illegal gold mining site in Igun, Osun State, Nigeria. J. Health Pollut. 2015;5:19-32.

5. Doctors Without Borders. Lead poisoning crisis in Zamfara State, Northern Nigeria. c2012. [Cited 30 November 2017]. Available from: http://www.doctorswithoutborders.org/newsstories/briefing-document/lead-poisoning-crisis-zamfarastate-northern-nigeria.

6. Bartrem C, Tirima S, von Lindern I, et al. Unknown risk: Co-exposure to lead and other heavy metals among children living in small-scale mining communities in Zamfara State, Nigeria.
Int. J. Environ. Health Res. 2014;24:304-319.

7. Tech ET. Determination of some heavy metals in wastewater and sediment of artisanal gold local mining site of Abare Area in Nigeria. J. Environ. Treat. Tech. 2013;1:174-182.

8. Abdu N, Yusuf A. Human health risk characterization of lead pollution in contaminated farmlands of Abare village, Zamfara State, Nigeria. Afr. J. Environ. Sci. Technol. 2013;7:911-916.

9. Mohammed I, Abdu N. Horizontal and vertical distribution of lead, cadmium, and zinc in farmlands around a lead-contaminated goldmine in Zamfara, Northern Nigeria. Arch. Environ. Contam. Toxicol. 2014;66:295-302.

10. Acosta JA, Faz A, Martínez-Martínez S, Zornoza R, Carmona DM, Kabas S. Multivariate statistical and GIS-based approach to evaluate heavy metals behavior in mine sites for future reclamation. J. Geochem. Explor. 2011;109:8-17.

11. Antunes IM, Albuquerque MT. Using indicator kriging for the evaluation of arsenic potential contamination in an abandoned mining area (Portugal). Sci. Total Environ. 2013;442:545-552.

12. Acosta JA, Faz Á, Martínez P, et al. Environmental risk assessment of tailings ponds using geophysical and geochemical techniques. In: Assessment, restoration and reclamation of mining influenced soils. 2017. p. 135-148.

13. Liang CP, Chen JS, Chien YC, Chen CF. Spatial analysis of the risk to human health from exposure to arsenic contaminated groundwater: A kriging approach. Sci. Total Environ. 2018;627:1048-1057.

14. Largueche FZ. Estimating soil contamination with Kriging interpolation method. Am. J. Appl. Sci. 2006;3:1894-1898.

15. Jia G, Taflanidis AA. Kriging metamodeling for approximation of high-dimensional wave and surge responses in real-time storm/hurricane risk assessment. Comput. Methods Appl. Mech. Eng. 2013;261:24-38.

16. Goovaerts P. Geostatistical approaches for incorporating elevation into the spatial interpolation of rainfall. J. hydrol. 2000;228:113-129.

17. Lin YP, Chang TK, Teng TP. Characterization of soil lead by comparing sequential Gaussian simulation, simulated annealing simulation and kriging methods. Environ. Geol. 2001;41: 189-199.

18. McGrath D, Zhang C, Carton OT. Geostatistical analyses and hazard assessment on soil lead in Silvermines area, Ireland. Environ. Pollut. 2004;127:239-248.

19. Tobler WR. A computer movie simulating urban growth in the Detroit region. Econ. Geogr. 1970;46:234-240.

20. Salati LK, Mireku-Gyimah D, Eshun PA. Evaluation of stakeholders' roles in the management of artisanal and small-scale gold mining in Anka, Zamfara State, Nigeria. Evaluation 2014;4:19.

21. Nigeria National Census. National Population Commission. 2006. Abuja, Nigeria.

22. USEPA. Exposure factors handbook. Office of Research and Development, Washington, DC, USA. 1997.

23. Man YB, Sun XL, Zhao YG, et al. Health risk assessment of abandoned agricultural soils based on heavy metal contents in Hong Kong, the world's most populated city. Environ. Int. 2010;36:570-576.

24. Wang Z, Chai L, Yang Z, Wang Y, Wang H. Identifying sources 
and assessing potential risk of heavy metals in soils from direct exposure to children in a mine-impacted city, Changsha, China. J. Environ. Qual. 2010;39:1616-1623.

25. Health Canada. Federal contaminated site risk assessment in Canada, Part V: Guidance on human health detailed quantitative risk assessment for chemicals (DQRAChem). c2010. [Cited 30 November 2017]. Available from: http://publications. gc.ca/collections/collection_2011/sc-hc/H128-1-11-639-eng. pdf.

26. USEPA. Supplemental guidance for developing soil screening levels for Superfund sites. Office of Solid Waste and Emergency Response, Washington D.C. 2002. OSWER 9355.4-24

27. Yuswir NS, Praveena SM, Aris AZ, Ismail SNS, Hashim Z. Health risk assessment of heavy metal in urban surface soil (Klang District, Malaysia). Bull. Environ. Contam. Toxicol. 2015;95:80-89

28. Chiroma TM, Ebewele RO, Hymore FK. Comparative assessment of heavy metal levels in soil, vegetables and urban grey waste water used for irrigation in Yola and Kano. Int. Refereed J. Eng. Sci. 2014;3:1-9.
29. Canadian Ministry of the Environment. Soil, ground water and sediment standards for use under Part XV.1 of the environmental protection act. Canadian Ministry of the Environment: Toronto, ON, Canada; 2009.

30. USEPA. Exposure factors handbook 2011 edition (Final report). U.S. Environmental Protection Agency, Washington D.C. EPA/600/R-09/052F, 2011.

31. USEPA. Screening Levels (RSL) for chemical contaminants at superfund sites. U.S. Environmental Protection Agency; 2011.

32. USDOE. The Risk Assessment Information System (RAIS). U.S. Department of Energy's Oak Ridge Operations Office (ORO); 2011.

33. USEPA. Risk-based Concentration Table. Philadelphia PA: United States Environmental Protection Agency, Washington D.C., USA; 2009.

34. USEPA. Integrated risk information system (IRIS). United States Environmental Protection Agency, Washington D.C., USA; 2010. 